DOI: $10.34185 / 1991-7848 . i t m m .2020 .01 .039$

КОМПЬЮТЕРНАЯ СИСТЕМА КОНТРОЛЯ ШЛАКОВОГО РЕЖИМА В СОВРЕМЕННЫХ УСЛОВИЯХ ДОМЕННОЙ ПЛАВКИ

Тогобицкая Д.Н., д.т.н., проф., Белькова А.И., к.т.н., Степаненко Д.А., к.т.н., Лихачев Ю.М., Скачко А.С., к.т.н.

Институт черной металлургии им. 3.И. Некрасова НАНУ, Украина

Аннотация. Рассмотрены функциональные возможности, методологические основы и информационно-программное обеспечение модернизированной компьютерной системы контроля шлакового режима доменной плавки, разработанной в Институте черной металлургии на базе фундаментальных основ в области физико-химического и математического моделирования металлургических расплавов и систем на основе концепции направленной химической связи. Система обеспечивает прогнозный расчет комплекса технологических свойств конечных доменных шлаков: вязкости, температур плавления, энтальпии и серопоглотительной способности. Оперативная оценка шлакового режима с помощью системы «Шлак» в составе АСУТП ДП позволяет эффективно и на современном уровне решать задачи оптимизации шлакового режима и качества чугуна в современных условиях доменной плавки.

Ключевые слова: компьютерная система, доменная плавка, шлаковый режим, физико-химические свойства, прогнозная модель.

В Институте черной металлургии НАНУ на базе фундаментальных разработок в области физико-химического моделирования расплавов создана и прошла промышленное испытание компьютерная система контроля шлакового режима доменной плавки «Шлак» на основе прогнозной оценки комплекса физико-химических свойств конечных доменных шлаков [1-2].

В связи с существенными изменениями сырьевых и энергетических условий производства чугуна, главным образом связанных с использованием отходов, различных соотношений кокса, природного газа и пылеугольного топлива, в системе выполнена соответствующая модернизация модельного и графического модулей.

Система обеспечивает: 
Ministry of Education and Science of Ukraine

The National Metallurgical Academy of Ukraine, Dnipro, 17 - 19 March, 2020

- контроль показателей продуктов плавки: химического состава и температуры чугуна, химического состава конечного шлака и показателей шлакового режима (основность $1 \mathrm{CaO} / \mathrm{SiO}_{2}$, основность $2(\mathrm{CaO}+\mathrm{MgO}) / \mathrm{SiO}_{2}$, отношение $\mathrm{Al}_{2} \mathrm{O}_{3} / \mathrm{MgO}$ ) в ретроспективе (рис. 1) для указанного диапазона выпусков или дат;

- расчет комплекса наиболее важных технологических свойств доменного шлака для указанного выпуска: серопоглотительной способности (Cs); вязкости $\left(\eta\right.$, Па.с) и поверхностного натяжения $(\sigma, \mathrm{MH} / \mathrm{M})$ для температуры $1500^{\circ} \mathrm{C}$ и температуры шлака, энтальпии при температуре хорошей текучести шлака $\left(\Delta \mathrm{H}\right.$, кДж/кг), температур начала (ликвидус, $\left.\mathrm{T}_{\text {л }},{ }^{\circ} \mathrm{C}\right)$ и конца (солидус, $\mathrm{T}_{\mathrm{c}},{ }^{\circ} \mathrm{C}$ ) кристаллизации; температуры гетерогенизации $T_{\varepsilon}$ и степени достижения системы «металл-шлак» равновесия по сере (є, \%) (рис. 2);

- оценку шлакового режима и выдачу управляющих рекомендаций в режиме Советчика мастеру ДП (рис. 2).

Прогнозирование свойств доменных шлаков в системе осуществляется с использованием разработанной физико-химической методологии описания структуры и свойств оксидных систем на уровне межатомного взаимодействия [2]. Ввод модельных параметров шлакового расплава - химического эквивалента состава $\Delta \mathrm{e}$ и стехиометрического параметра $\rho$ - позволяет прогнозировать свойства в зависимости от изменения химического состава шлака по моделям: Свойство $=\mathrm{f}(\Delta \mathrm{e}, \rho, \mathrm{T})$, где T - температура расплава [1].

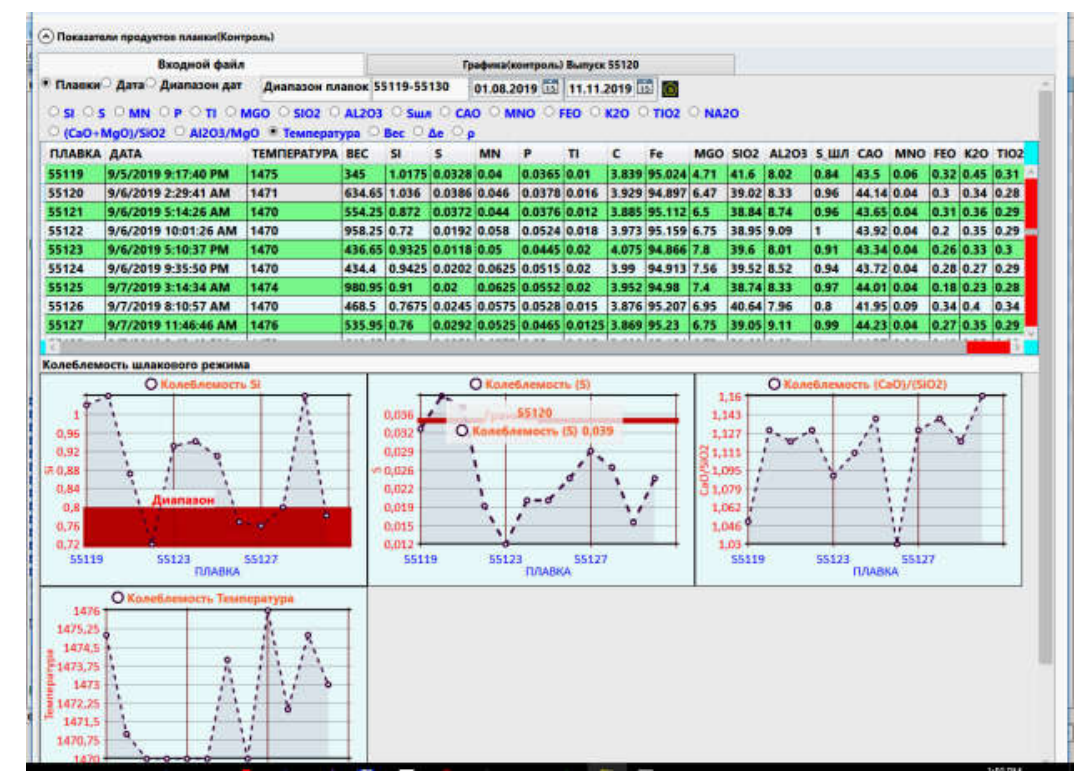

Рисунок 1 - Контроль показателей продуктов плавки в системе «Шлак» 
International scientific and technical conference Information Technologies in Metallurgy and Machine building - ITMM 2020

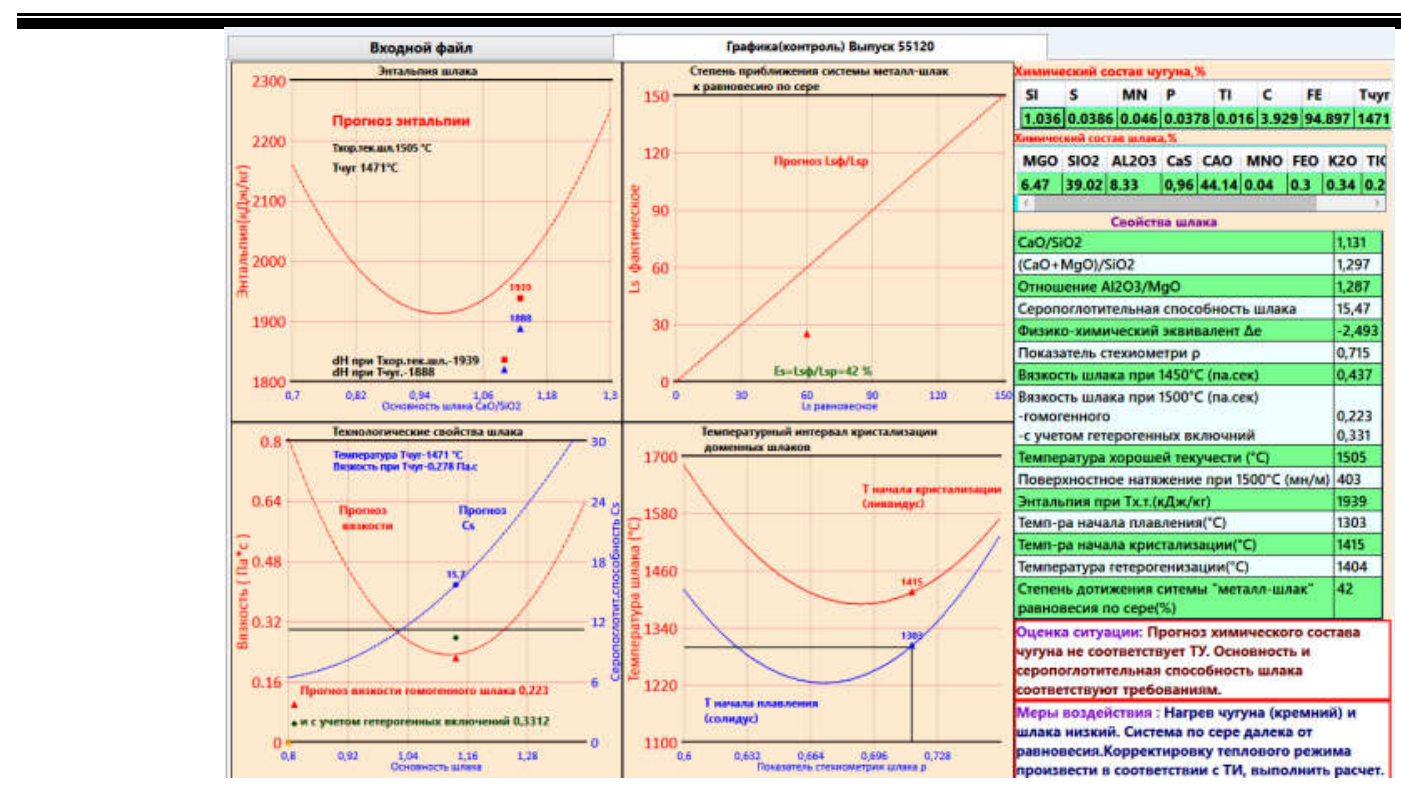

Рисунок 2 - Оценка шлакового режима в системе «Шлак»

Вязкость характеризует текучесть шлака и обеспечивает десульфурирующие и дренажные свойства. Расчет вязкости для указанного выпуска чугуна по химическому составу шлака осуществляется по базовой модели шлака в условно «гомогенном» состоянии и с учетом его гетерогенности, обусловленной наличием макрогетерогенных включений, образующихся при использовании кокса с низкими прочностными характеристиками и вследствие неполного сжигания пылеугольного топлива в печи. При этом вязкость по базовой модели рассчитывается при температуре $1500^{\circ} \mathrm{C}$, а также может быть определена для заданной температуры шлака на выпуске.

На графике зависимости вязкости конечного шлака при температуре $1500^{\circ} \mathrm{C}$ от основности шлака $\mathrm{CaO} / \mathrm{SiO}_{2}$ отмечена величина оптимальной вязкости 0,3 Па.с (рис. 2). При увеличении вязкости более 0,3 Па·с уменьшается диффузионная подвижность шлакового расплава и ухудшаются кинетические условия обессеривания чугуна шлаком как в области «кислых» составов, так и «основных», когда шлак становится гетерогенным. При уменьшении вязкости менее 0,3 Па·с и, в особенности, менее 0,2 Па·с диффузионная подвижность шлака возрастает настолько, что он становится «агрессивным» по отношению к огнеупорам и футеровке печи.

На графике зависимости температуры начала плавления (солидус) шлака $\left(\mathrm{T}_{\mathrm{C}}\right)$ от параметра $\rho$ отмечена величина оптимальной температуры $\mathrm{T}_{\mathrm{C}}=1300^{\circ} \mathrm{C}$. Более высокая температура $\mathrm{T}_{\mathrm{C}}$ приводит $\mathrm{k}$ образованию гарниссажа и сокращению рабочего пространства горна. 
Энтальпия характеризует затраты тепла на образование шлака, нагрев его до заданной температуры, а также количество тепла, принесенного шлаком в горн. В системе реализован расчет энтальпии шлака при температуре хорошей текучести, соответствующей вязкости 0,3 Па.с, и заданной температуре шлака. При оптимизации шлакового режима доменной плавки для снижения расхода топлива предпочтение следует отдавать шлакам с минимальной избыточной энтальпией, обеспечивающей достаточный нагрев горна.

Степень реализации потенциальных возможностей серопоглотительной способности шлака в системе оценивают путем расчета степени приближения системы «металл-шлак» на выпуске из печи к равновесию по сере. Близость фактического коэффициента распределения серы $\left(\mathrm{Ls}_{\text {факт }}\right)$ к равновесному $\left(\mathrm{Ls}^{\mathrm{O}}\right)$ характеризует степень завершенности процесса десульфурации чугуна шлаком.

Таким образом, основными оптимальными значениями критериев являются вязкость шлака в пределах 0,3 Па.с и температура начала плавления 1300 C. В этом случае шлаки имеют хорошую текучесть, достаточную диффузионную подвижность и имеют тепловой резерв для реализации десульфурации чугуна. В случае несоответствия прогнозных значений свойств указанным величинам, что отображается на графиках видеокадра системы, изменяют химический состав и расход компонентов доменной шихты таким образом, чтобы вязкость конечного шлака составляла не более 0,3 Па.с и температура $\mathrm{T}_{\mathrm{C}}$ не более $1300^{\circ} \mathrm{C}$.

Программные средства системы «Шлак» разработаны с использованием языка C\# (Net 4.0, оболочка WPF). Графическая реализация объектов выполнена в оболочке WPF на базе пакета программ LiveCharts. Использование С\# и LiveCharts позволяет в перспективе развить программные средства системы «Шлак» до Web-версии путем применения сервера IIS Microsoft.

Внедрение алгоритмических и программных средств системы «Шлак» в системах АСУТП доменных печей обеспечивает технологов инструментальными средствами для выбора оптимального шлакового режима доменной плавки в современных нестабильных сырьевых условиях с целью получения чугуна требуемого химического состава с минимальными энергетическими и сырьевыми затратами. 


\title{
Литература
}

1. Тогобицкая Д.Н. Алгоритмические и программные средства системы контроля и управления шлаковым режимом доменной плавки / Д.Н. Тогобицкая, А.И. Белькова, А.Ю. Гринько, Д.А. Степаненко // Системные технологии. Региональный сборник научных трудов.- Днепропетровск. - 2013. - Вып. 3 (86). - С. 9-14.

2. Приходько Э.В. Прогнозирование физико-химических свойств оксидных систем / Э.В. Приходько, Д.Н. Тогобицкая, А.Ф. Хамхотько, Д.А. Степаненко. - Днепропетровск: Пороги. - 2013. - 339 с.

\section{COMPUTER SYSTEM OF CONTROL OF SLAG MODE IN MODERN BLAST FURNACE CONDITIONS}

\author{
Tohobytska Daria, Bielkova Alla, Stepanenko Dmytro, \\ Likhachov Yurii, Skachko Oleksandr
}

\begin{abstract}
The functional capabilities, methodological foundations and information software of a modernized computer system for controlling the slag regime of blast furnace smelting, developed at the Institute of Ferrous Metallurgy on the basis of fundamental principles in the physicochemical and mathematical modeling of metallurgical melts and systems based on the concept of directional chemical bonding, are considered. The system provides a predictive calculation of the complex of technological properties of the final blast furnace slag: viscosity, melting points, enthalpy, and desorption capacity. Operational assessment of the slag regime using the Slag system as part of the process control system allows efficiently and up-to-date solving the problems of optimizing the slag regime and pig iron quality under unstable blast furnace conditions
\end{abstract}

Key words: COMPUTER SYSTEM, BLAST-FURNACE SMELTING, SLAG MODE, PHYSICOCHEMICAL PROPERTIES, FORECAST MODEL.

\section{References}

1. Togobitskaya D.N. Algorithmic and software tools for monitoring and controlling the slag regime of blast furnace smelting / D.N. Togobitskaya, A.I. Bel'kova, A.Yu. Grin'ko, D.A. Stepanenko // System Technologies. Regional collection of scientific papers. Dnepropetrovsk. - 2013. - Issue. 3 (86). - S. 9-14.

2. Prikhodko E.V. Prediction of the physicochemical properties of oxide systems / E.V. Prikhod'ko, D.N. Togobitskaya, A.F. Hamhot'ko, D.A. Stepanenko. - Dnepropetrovsk: Thresholds. - 2013. - 339 p. 